\title{
The Strategies of NOx Emission Reduction for Diesel Engines
}

\author{
Dao Nam Cao, and Van Vang Le
}

\begin{abstract}
Diesel engines are more efficient than forced ignition engines but due to diffused combustion and work with high air residue levels, burning products contain soot and NOx, pollutants that work Handling it on the road today still has many technical problems. The technology of organizing the combustion of diesel engines directly affects the level of pollution generated. Direct injection diesel engines have a lower fuel consumption than a combustion engine with a separation of about $10 \%$ and a lower level of soot emissions when the engine is operating in local loading mode. However, direct injection engines work noisier and generate more pollutants (NOx, HC). Today, this type of combustion chamber is only used for heavy-duty truck engines. Limiting the optimal emission level for diesel engines needs to balance the concentration of the two main pollutants, NOx and soot. Low temperature combustion (LTC) engines need different enabling technologies depending on the fuel and strategy used to achieve combustion of the premixed fuel-air mixture. Controlling the combustion rate is one of the major challenges in LTC engines, particularly in PPCI combustion engine to achieve higher thermal efficiency, the desired phasing of combustion timings is essential even at moderate combustion rates. Present chapter describes the combustion control variables and control strategies used for LTC engines. Various methods demonstrated to control the LTC engines can be categorized in to two main strategies: (i) altering pressure-temperature and (ii) altering fuel reactivity of the charge.
\end{abstract}

Index Terms-Diesel Engines; Low Temperature; NOx Emission; Thermal Efficiency; Alternative Fuel.

\section{INTRODUCTION}

Of the total emissions polluting the urban air environment, emissions from road motor vehicles occupy the leading position. Among motor vehicles, motorcycles and motorbikes account for the largest proportion, and also the largest source of pollutant emissions. Emissions from road vehicles are shown to be highly dependent on vehicle quality, fuel, speed, driver, congestion and roads. Automobiles and motorbikes include many types of vehicles, many have been used for many years and are not regularly maintained, low fuel efficiency, high toxicity and dust emissions. Motorbikes are still the main source of pollutant gases, especially for emissions such as $\mathrm{CO}$ and VOC. Meanwhile, trucks and passenger cars waste more $\mathrm{NO} 2, \mathrm{SO} 2$ [1]-[3]. Insufficient burning of the fuel also releases carbon dust. This dust is usually left on the road, or sticking to the car and often rolling on the tires when the car is running is also considered as the agent from traffic emissions. Explaining the cause of the problem, experts say

Published on November 21, 2018

D. N. Cao, V. V. Le are with Ho Chi Minh city University of Transport, Ho Chi Minh city, Vietnam. that motorized vehicles use gasoline and diesel as a fuel, leaks, and evaporates and burns fuel, which also leads to many types of emissions and toxic gas such as VOC, Benzene, Toluene. There are many methods to reduce toxic emissions such as: interfering with the engine structure, regulating the combustion process, using alternative fuels The effect of injection system quality on direct injection engines is greater for indirect injection engines in terms of generation of pollution. In both cases, the early angle change variation has the opposite effect for the generation of NOx, $\mathrm{HC}$ and soot. The early spray angle increases the maximum pressure and combustion temperature, thus increasing NO concentration. Normally, the direct injection engine has a higher early angle of injection, resulting in more NO than the engine with separate combustion chamber. Reducing the angle of injection is an effective way to reduce the NOx concentration in the exhaust gas. On the other hand, when the spray angle is increased early, due to prolonged fires, the amount of fuel mixed before the high air mass ratio increases. This mixture is difficult to fire so they often burn incompletely and generate more CO. Theoretically, increasing the early ignition angle can reduce $\mathrm{HC}$ due to the more favorable combustion process, but in practice it has the opposite effect. Indeed, due to the prolonged fire-fighting time, the fuel can be trapped on the combustion chamber wall, which is the source of the HC [4]-[6]. For direct injection engines, the reduction in early spray angle increases the smoke and also increases the fuel consumption but reduces NOx and SOF. For larger diesel engines, reducing early spray angle can reduce NO concentration in the exhaust gas by $50 \%$. For engines with separate combustion chambers, an early injection angle reduces the concentration of NOx and soot, especially at full load. When the angle of spraying was changed from 8 to 23 degrees before TDCT, the amount of soot doubled according to the FTP75 test cycle for a combustion engine with a normal early 15-degree angle of ignition before CO. The early spray angle change is suitable according to the speed and load allowing the optimum adjustment position between the concentration of pollutants and the engine efficiency. For engines with a backup combustion chamber, optimum ignition timing control by electronic system in speed mode and load mode allows 15\% NOx reduction and 25\% FTP75 test in the area of increased fuel consumption is not significant. High spray rate (due to increased spray pressure) affects the emission of direct injection engines. Indeed, due to the increased mixing speed of the fuel and air, the amount of fuel burned in the pre-mixing condition increases, so the NOx concentration increases but the amount of soot is reduced. However, the increase in spray pressure (more than $100 \mathrm{MPa}$ ) increased the amount of solids due to the increase 
in SOF. Using a spray nozzle with multiple diaphragm sprays increases the quality of air and fuel blending due to reduced particle size, the mixture burns more easily, compensating for latex emissions thus reducing NOx. With the same amount of NOx emissions, an increase in the number of holes reduces the concentration of soot. For direct injection engines, the optimum injection pressure varies from 75 to $100 \mathrm{MPa}$ depending on engine mode. Exceeding this pressure, with the same amount of NOx generated, the amount of solid particles produced decreases but the fuel consumption and noise of the combustion process increase due to the sudden increase in pressure. This can be overcome by using a spray of primer. The spray rule also has an important influence on the generation of pollutants. Shorter spraying time, high injection pressure allows accelerated fuel delivery, resulting in less burnout. Recent advances in spray technology to reduce pollution levels include the two-stage spray rule, the 'rectangular' spray rule (regular spraying and fast cutting at the end of the spray) to avoid spraying phenomenon. Spray-down is the cause of increased unburned hydrocarbons and solid particles in the exhaust gas of the engine. For engines with separate combustion chambers, the control of fuel flow with reduced spray angle can reduce NOx emissions by $30 \%$ in the exhaust gas, but increases the $\mathrm{HC}$ content to $100 \%, \mathrm{CO}$ up to $70 \%$ up to $150 \%$ [7]-[11]. In order to ensure proper spray regulation at all working modes of the engine both in terms of emission and technical and economic features, the current generation sensors $\lambda$ on the discharge line. Combined with this sensor, pressure sensors, intake air temperature and engine speed, it is possible to accurately control the timing of the injection and the amount of fuel supplied per cycle. This solution is particularly beneficial for diesel engines mounted on cars to reduce the amount of smoke acceleration. Reducing the air temperature will reduce the maximum temperature of the combustion process and therefore the NOx concentration will also decrease. Thus, in the turbocharged engine there is a tendency to cool the air behind the compressor to ensure that the intake air temperature does not exceed $50 \mathrm{oC}$, intercooler cooling can prolong the ignition time, which increases the level of pollution generated (the droplets that stick to the cylinder walls increase the $\mathrm{HC}$ content and the soot in the exhaust gas). When the engine starts to cool, the drying of the combustion chamber or the air-drier is necessary to reduce the amount of $\mathrm{HC}$ and white smoke. Intruder drying can be accomplished by electric candles or by pre-burning some of the fuel in the air. The temperature of the waste gas also affects the generation of pollution, especially for $\mathrm{HC}$ components. Indeed, in low load mode, HC condenses on the exhaust and evaporates again as the load increases, increasing the $\mathrm{HC}$ concentration. Emissions from ceramic materials allow for the re-oxidation of soot and $\mathrm{HC}$, but increase NOx. Direct-injection diesel engines have a ceramic-free combustion chamber that reduces the concentration of pollutants in low-load mode. But when the load is high, NOx and soot concentrations increase despite the high temperature of the combustion chamber allowing re-burning of soot at the end of the cycle.

\section{Altering Pressure-Temperature}

Time-temperature of the charge in the cylinder determines the combustion timings, which essentially governs the combustion rate and thermal efficiency. In different LTC strategies, charge temperature is controlled to achieve desired combustion phasing and extend the engine operating load. Temperature and pressure of charge in the cylinder is correlated by gas equations. The time temperature of the charge is affected by several engine operating parameters. Appropriate thermodynamic and chemical in-cylinder conditions are required in a PPCI combustion close to TDC position to achieve the autoignition at desired combustion phasing. Additionally, the air-fuel mixture in PPCI combustion needs to be sufficiently dilute to keep combustion rates and maximum charge temperature low enough to achieve acceptable ringing intensity and NO x emissions.

\section{A. Exhaust Gas Recirculation}

Exhaust gas recirculation (EGR) is a well-established method for facilitating control over ignition and combustion phasing, which affects the combustion performance in $\mathrm{CI}$ engines. The EGR is broadly divided in two category (internaland external EGR) based on induction method in the cylinder. In external EGR (eEGR), a faction of exhaust gases from engine tailpipe is recirculated back into the intake manifold by typically passing through an EGR cooler. However, in case of internal EGR (iEGR), hot residual gases are trapped in the cylinder by changing the valve timings. The use of EGR changes the charge composition and charge mixture properties as the thermodynamic and chemical properties of EGR are significantly different than air. EGR typically consists of significant amount of complete combustion products $\left(\mathrm{CO}_{2}\right.$ and $\left.\mathrm{H}_{2} \mathrm{O}\right)$ and a large variety of incomplete combustion products, some of which is trace quantity. The EGR as a diluent has the potential to significantly alter and affect combustion characteristics including burn rates, ignition timing, combustion and engine thermal efficiencies.

In internal EGR, trapping of hot residuals from the previous cycle is achieved by the using flexible valve trains. Desired amount of internal EGR is obtained by adjusting the valve lift and valve timings (typically NVO) depending on engine operating conditions. In internal EGR, trapping of hot residuals from the previous cycle is achieved by the using flexible valve trains. Desired amount of internal EGR is obtained by adjusting the valve lift and valve timings (typically NVO) depending on engine operating conditions. In NVO strategy, the exhaust valve is closed early and a fraction of exhaust gas trapped in the cylinder undergo "recompression" due motion of piston towards TDC. The trapped residual gases subsequently mix with the cooler fresh incoming charge. Mixing of the fresh charge with the hot residual gases leads to overall increase in the charge temperature, which facilitate to achieve auto-ignition in PPCI combustion. In conventional engines, in contrast to NVO, the positive valve overlap (PVO) is typically used where both the exhaust and intake valves are open simultaneously for a short time period around the intake TDC position. Fig. 1 illustrates the PVO and NVO valve lift profiles along with corresponding typical cylinder pressure 
trace. The PVO shown in figure has negligible overlap between intake and exhaust events, but it can vary depending on engine speed. Fig. 1 also shows that advance in exhaust valve closing (EVC) timing is complemented by a corresponding and equal retard in intake valve open (IVO) timing in case of the NVO, and this strategy is called "symmetric" NVO. This strategy is employed to minimize the pumping losses related to recompression.
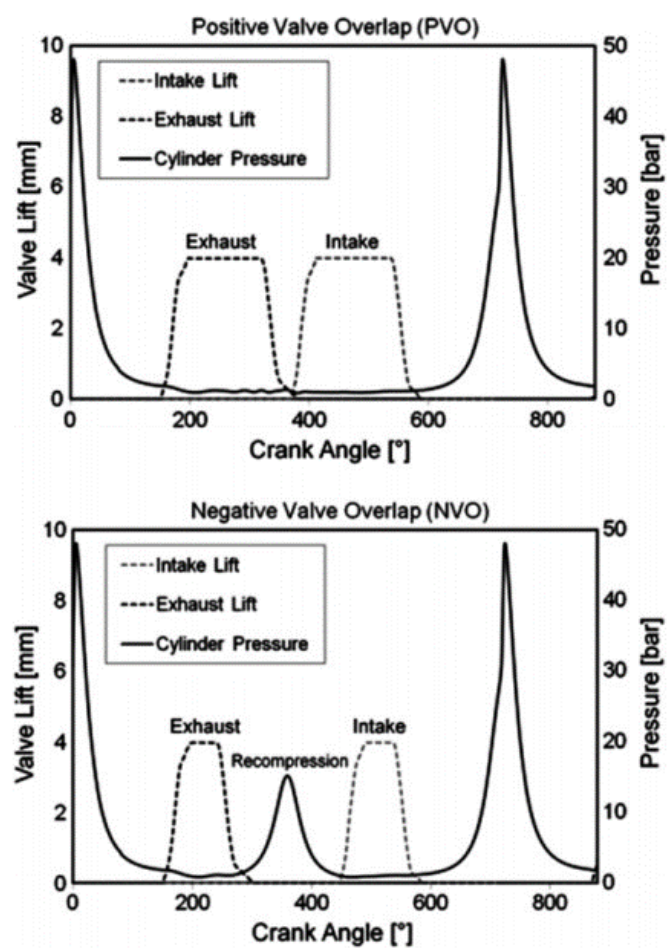

Fig. 1. The PVO and NVO valve lift profiles along with typical cylinder pressure curve

Fig. 2 presents the EGR flow rate as a function of engine load and fuel type in PPC engine for different compression ratios. At higher compression ratio (18), EGR flow rate around $50 \%$ is required for higher engine load, and low octane fuel has lower requirement of EGR. At lower compression ratio, lower octane gasoline and ethanol have lower EGR requirement for low load conditions. The EGR requirement depends on fuel, compression ratio, injection timings and intake pressure used for PPC combustion. The EGR rate shown in Fig. 2 is for injection strategy (two direct injection per cycle) developed in reference.

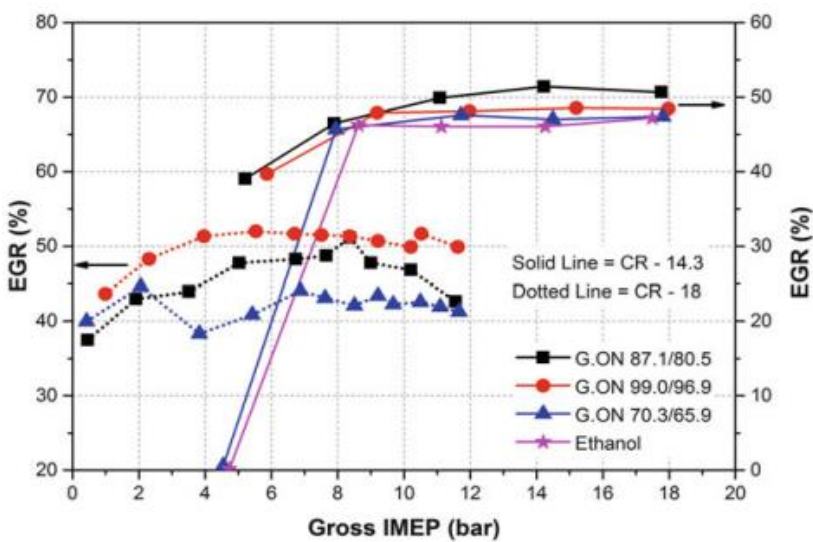

Fig. 2. EGR rate as a function of engine load and fuel type in PPC engine for different compression ratios

\section{B. Variable Valve Actuation}

Variable valve actuation (VVA) offers a very fast method of varying the breathing process of the engine. In variable valve actuation strategy, mainly variable valve timing (VVT) and/or variable valve lift (VVL) is used to (i) control the residual gases in the cylinder and (ii) vary the effective compression ratio of the engine.

Fig. 3 shows the summary of trade-off observed in reduction of effective compression ratio using VVA by presenting positive as well as negative impacts. The reduction in effective compression ratio must have a positive effect on NOx emission due to decrease in pressure and temperature in the engine cylinder. However, a major effect is the decrease in volumetric efficiency resulting into decrease in EGR rate at particular intake pressure and equivalence ratio, which leads to higher NOx. Similar tradeoff is observed for smoke emissions. Reduction in compression ratio increases the ignition delay thus more premixed combustion leads to reduction in smoke, while decrease in the volumetric efficiency produces opposite result. In case of $\mathrm{HC}$ and $\mathrm{CO}$ emissions, the combustion temperature increase leads to decrease in these emissions but the lower effective compression ratio also lower the charge temperature during injection phase leading to lower vaporization, which creates a negative effect.

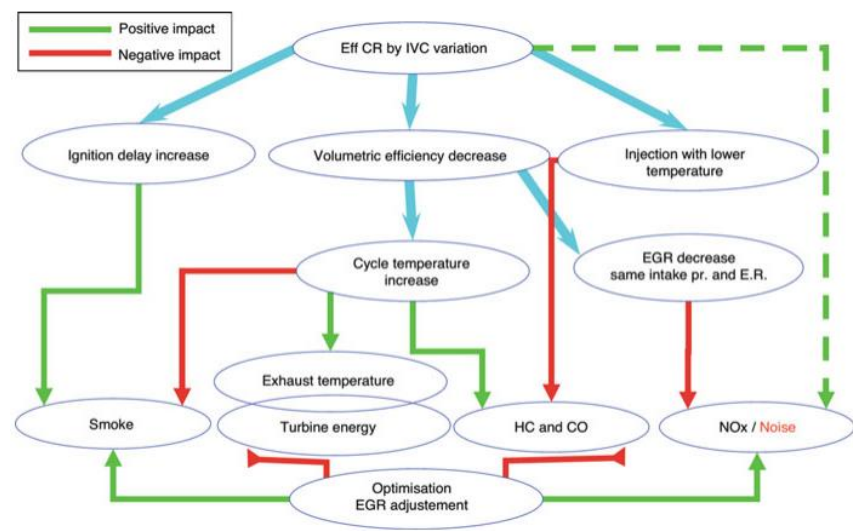

Fig. 3. Summary of trade off observed in reduction of effective compression ratio using VVA strategy

\section{Water Injection}

A study used water injection to control diesel PPCI combustion timing and demonstrated that water injection could reduce the heat release rate significantly. Direct water injection (using diesel fuel injector) is used to extend the load range of premixed compression ignition The study showed that the combustion suppression effect increases with increase in water injection quantity, and excessive water injection leads to higher THC emission along with lower thermal efficiency. Although the reaction suppressing effect of water injection enhances with advanced timings, an optimum water injection timing occurs. With more advanced timings, water vaporization is delayed, which decreases the reaction suppressing effect. Thus, amount of water injection must be limited to the minimum required for sufficient suppression of oxidation reactions at excessively advanced combustion timings. 


\section{Boosting}

Boosting (increasing intake air pressure) is considered as an effective technique to increase the engine operating load and extend the operational range of air-fuel ratio in PPCI combustion mode. However, boosting is accompanied by a higher peak cylinder pressure, which may lead to reach peak pressure limit of the engine. Higher intake pressure can enable an increase of the overall dilution of fuel-air mixture and affect the combustion characteristics through chemical effects related to the higher pressure of combustion chamber. At particular fuelling rate, relatively larger amount of inducted mass at higher intake pressure leads to higher level of charge dilution leads to reduction in pressure rise rates in PPCI combustion. For a fixed pressure rise rate limit, relatively higher amount of fuel can be burned in the cylinder and thus the maximum load limit increases via intake boosting.

\section{E. In-Cylinder Injection Strategies}

The local charge temperature and the air-fuel ratio are the key parameters controlling the initiation of PPCI combustion process. The direct injection of fuel into the cylinder provides the potential to control the combustion process by altering the local fuel concentration by varying the injection timings. The gas temperature is also altered through the charge cooling from fuel evaporation. Early fuel injection timings provide sufficient time for fuel vaporization and mixing with the air to create a premixed fuel-air mixture [12-[17]. The late pilot injection in the cylinder during compression stroke can control the combustion phasing by creating fuel stratification (increasing the local fuel concentration in some regions) in the cylinder. Additionally, rich mixture decreases the ratio of specific heat and thus amount of disposable compression heating in the charge. Consequently, mixture has to be further compressed to reach the autoignition temperature. The capability of split injection can combine these two functions.

\section{ALTERING FUEL REACTIVITY}

Altering reactivity (autoignition characteristics) of fuelair mixture is another strategy to control the combustion rate and combustion phasing in LTC engines. Mixture autoignition properties are affected by fuel types, fuel concentration, blending of two or more fuels, fuel additives, residual rate and residual reactivity, boosting etc. In this section, LTC controlled by altering the fuel reactivity using different strategies is presented.

\section{A. In-Cylinder Fuel Stratification}

Fuel stratification in the cylinder is created by direct injection of fuel. Fuel stratification is one of the main methods to control the combustion rate by increasing the combustion duration. Fuel stratification is typically used to increase the engine operating load of LTC engines. A recent study demonstrated the direct injection of gasoline (by dual pulse) increases the thermal efficiency of partially stratified PPCI combustion. PPC combustion also creates heavy stratification in the cylinder by using fuel injection system of diesel engine for gasoline-like fuels.

\section{B. Dual Fuel}

Fuel auto-ignition property variation can be used as a method for PPCI combustion control. The combustion phasing can be controlled by varying the fuel properties, and thus operating range can also be expanded. A study investigated the effect of fuel properties on low and high temperature heat release of PPCI combustion and its performance. Fuel composition affects the low temperature heat release (LTHR) and high temperature heat release (HTHR) values. Fuel stratification in the cylinder leads to retarded combustion phasing, and it provides an additional actuator for PPCI combustion control. However, very large stratification may lead to unstable combustion [17]-[19].

Dual fuel method can be used to actively vary the fuel octane number. The idea of using dual fuels is to use two fuels with different auto-ignition reactivity. The dual fuel system has a main fuel with a high octane number and a secondary fuel with low octane number (high cetane number). This feature can then be used to control the combustion phasing in PPCI as blending the two fuels at different fuel ratio changes the auto ignition properties. Injection of low octane fuel in higher quantity leads to earlier auto-ignition in the cylinder. For advanced combustion phasing, the secondary fuel quantity is increased. For individual cylinder control of the combustion phasing, each cylinder must have two injectors for two different reactivity fuels. The benefit with dual fuels operation is that it provides an accurate control without any large engine modifications and cost. Only additional injectors are required. One demerit of this system is the requirement of two fuel tanks and its refuelling. However, secondary fuel consumption is very low and could be refuelled only in the maintenance intervals. Typically, this system is demonstrated with fuel injection in the port by external blending of the fuels.

\section{Fuel Additives}

Selection of appropriate fuel is a key aspect of LTC engine design and development. Auto-ignition characteristics and fuel volatility are the key variables in the fuel selection. In order to easily create premixed charge, fuel needs to have high volatility characteristics. Chemically, single-stage heat release fuels have lower sensitivity to variations in engine load and speed. Lower sensitivity to variations makes the requirements on PPCI control system easier over a wide range of operating conditions. To achieve high fuel conversion efficiency, fuel auto-ignition temperature is critical parameter for selection of an optimum geometrical compression ratio of the engine. Required fuel in PPCI combustion needs to satisfy the requirements over wide range of engine loads (low to high load). At lower engine loads, low octane fuel is required to facilitate the auto-ignition, while at higher engine loads relatively higher octane fuel is required to avoid the knocking during combustion [20]-[24]. This opposing requirement leads to difficulty in PPCI engine development, and there exists no universal fuel that satisfies the specific requirement of PPCI combustion engine. The optimal fuel selection is influenced by the combustion control strategies used in LTC engine and engine operating conditions. Thus, LTC engines can be operated on any fuel, but adaptation is required either fuel to 
specific engine design or engine to a specific fuel or even a specific engine operating condition.

\section{CONCLUSION}

Several methods are proposed to address the cold start in HCCI engines such as the use of spark plugs, increased compression ratios by VCR or VVT and the use of different fuels or fuel additives. The most practical approach to dealing with cold start in HCCI engines is to start the engine in normal SI or CI mode and switch to HCCI mode after the engine is hot. Air preparation is pre-mixed efficiently and avoids interactions of the fuel wall that are required in the HCCI engine for higher fuel conversion efficiency and lower emissions. This problem is often associated with the poor fluctuation of diesel in the HCCI engine because of the inhomogeneity that affects the combustion and timing control of HCCI engines. To prepare the full range of premixed fuel in the HCCI engine, the volatile fuel injection nozzle, and the early injection of fuel into the cylinder with sophisticated injectors for volatile fuels such as diesel are recommended. In order to solve the problem of shorter ignition timing, low cetane (high octane) fuel was used in the PPCI mode, NOx and carbon black were obtained with moderate EGR (50\%) at pressure Medium (IMEP) 15 bar. The combustion efficiency is up to $98 \%$ even when operating the engine with a $50 \%$ EGR. This result led to further research on low cetane fuels (with high octane ratios, such as gasoline) in PPCI engines.

\section{REFERENCES}

[1] Y.-C. Lin, K.-H. Hsu, and C.-B. Chen, "Experimental investigation of the performance and emissions of a heavy-duty diesel engine fueled with waste cooking oil biodiesel/ultra-low sulfur diesel blends," Energy, vol. 36, no. 1, pp. 241-248, 2011.

[2] T. A. Hoang, N. X. Chu, and T. Van Tran, "The Environmental Pollution In Vietnam: Source, Impact And Remedies," Int. J. Sci. Technol. Res., vol. 6, no. 2, pp. 249-253, 2017.

[3] A. T. Hoang, "Waste heat recovery from diesel engines based on Organic Rankine Cycle," Appl. Energy, vol. 231, pp. 138-166, 2018.

[4] S. Ushakov, H. Valland, J. B. Nielsen, and E. Hennie, "Effects of high sulphur content in marine fuels on particulate matter emission characteristics," J. Mar. Eng. Technol., vol. 12, no. 3, pp. 30-39, 2013.

[5] A. T. Hoang, Q. V. Tran, and X. D. Pham, "Performance and Emission Characteristics of Popular 4-Stroke Motorcycle Engine in Vietnam Fuelled with Biogasoline Compared with Fossil Gasoline," Int. J. Mech. Mechatronics Eng., vol. 18, no. 2, pp. 97-103, 2018.

[6] A. T. Hoang and V. T. Nguyen, "Emission Characteristics of a Diesel Engine Fuelled with Preheated Vegetable Oil and Biodiesel," Philipp. J. Sci., vol. 146, no. 4, pp. 475-482, 2017.

[7] V. D. Tran, A. T. Le, V. H. Dong, and A. T. Hoang, "Methods of operating the marine engines by ultra-low sulfur fuel to aiming to satisfy MARPOLAnnex VI," Adv. Nat. Appl. Sci., vol. 11, no. 12, pp. 34-40, 2017
[8] T. A. Hoang and V. Van Le, "The Performance of A Diesel Engine Fueled With Diesel Oil, Biodiesel and Preheated Coconut Oil," Int. J. Renew. Energy Dev., vol. 6, no. 1, pp. 1-7, 2017.

[9] A. T. Hoang, M. M. Noor and X. D. Pham, "Comparative Analysis on Performance and Emission Characteristic of Diesel Engine Fueled with Heated Coconut Oil and Diesel Fuel," Int. J. Automot. Mech. Eng., vol. 15, no. 1, pp. 5110-5125, 2018.

[10] A. T. Hoang, "A report of the oil spill recovery and treatment technologies to reduce the marine environment pollution," Int. J. $e$ Navigation Marit. Econ., vol. 9, pp. 35-49, 2018.

[11] A. T. Hoang and V. V. Pham, "Impact of Jatropha Oil on Engine Performance, Emission Characteristics, Deposit Formation, and Lubricating Oil Degradation," Combust. Sci. Technol., 2018 https://doi.org/10.1080/00102202.2018.1504292.

[12] A. T. Hoang, "A Design and Fabrication of Heat Exchanger for Recovering Exhaust Gas Energy from Small Diesel Engine Fueled with Preheated Bio-oils," Int. J. Appl. Eng. Res., vol. 13, no. 7, pp. 5538-5545, 2018.

[13] A. T. Hoang, C. N. Luong, and A. T. Le, "Properties and Spray Characteristics of Heated Pure Coconut Oil Aiming a Direct Use in Conventional Diesel Engines," in The 5th TSME International Conference on Mechanical Engineering, 2014.

[14] B.-H. Lin, B.-X. Shen, and J.-G. Zhao, "A study on the prediction model for the lubricity of hydrogenated ultra-low sulfur diesel fuel," Energy Sources, Part A Recover. Util. Environ. Eff., vol. 33, no. 3, pp. 254-264, 2010.

[15] A. T. Hoang and A. T. Le, "A review on deposit formation in the injector of diesel engines running on biodiesel," Energy Sources, Part A Recover. Util. Environ. Eff., 2018. https://doi.org/10.1080/15567036.2018.1520342.

[16] A. T. Hoang, "The Performance of Diesel Engine Fueled Diesel Oil in Comparison with Heated Pure Vegetable Oils Available in Vietnam," J. Sustain. Dev., vol. 10, no. 2, pp. 93-103, 2017.

[17] V. V. Le, D. C. Nguyen, and A. T. Hoang, "The potential of using the renewable energy aiming at environmental protection," Int. J. Latest Eng. Res. Appl., vol. 2, no. 7, pp. 54-60, 2017.

[18] A. T. Hoang and V. V. Pham, "A study of emission characteristic, deposits, and lubrication oil degradation of a diesel engine running on preheated vegetable oil and diesel oil," Energy Sources, Part A $\begin{array}{llll}\text { Recover. } & \text { Util. } & \text { Environ. } & \text { Eff., }\end{array}$ https://doi.org/10.1080/15567036.2018.1520344.

[19] A. T. Hoang and D. N. Cao, "Some methods of reducing NOx components in exhaust gas," Int. J. Eng. Res. Manag. Stud., vol. 4, no. 5, pp. 11-18, 2017.

[20] A. T. Hoang, "Prediction of the density and viscosity of biodiesel and the influence of biodiesel properties on a diesel engine fuel supply system," J. Mar. Eng. Technol., 2018 . https://doi.org/10.1080/20464177.2018.1532734.

[21] V. V. Le and A. T. Hoang, "Fuel and alternative fuel for marine diese engines," International Journal of Recent Engineering Research and Development, vol. 2, no. 7, pp. 142-146, 2017.

[22] A. T. Hoang and M. T. Pham "Influences of heating temperatures on physical properties, spray characteristics of bio-oils and fuel supply system of a conventional diesel engine," International Journal on Advanced Science, Engineering and Information Technology, vol. 8, no. 5, pp. 2231-2240, 2018.

[23] Minh Tuan Pham, Anh Tuan Hoang, Anh Tuan Le, Abdel Rahman M.Said Al-Tawaha, Van Huong Dong and Van Vang Le "Measurement and Prediction of the Density and Viscosity of Biodiesel Blends," International Journal of Technology, vol. 9, no. 5, pp. 1015-1026, 2018.

[24] A. T. Hoang and V. V. Le, "Marine pollution and remedies of Vietnamese Government," Int. J. Recent Eng. Res. Dev., vol. 2, no. 4, pp. 51-55, 2017. 